\title{
Management of acute esophageal variceal bleeding by endoscopic sclerotherapy in technically difficult endoscopic band ligation cases-A population based cohort study
}

\author{
Gamal E. Esmat ${ }^{1}$, Iman M. Hamza ${ }^{1}$, Bahaa E. Abbas ${ }^{2}$, Ahmed M. Hashem ${ }^{1}$, Hossam S. Ghoneim ${ }^{3}$ \\ ${ }^{1}$ Endemic Medicine Department, Division of Endoscopy, Cairo University, Giza, Egypt \\ ${ }^{2}$ Division of Endoscopy, Air Force Hospital, Cairo, Egypt \\ ${ }^{3}$ Tropical Medicine Department, Beni Sweif University, Cairo, Egypt \\ Email: ${ }^{\text {iman_hamza@hotmail.com }}$ \\ Received 14 June 2013; revised 15 July 2013; accepted 29 July 2013 \\ Copyright (C) 2013 Gamal E. Esmat et al. This is an open access article distributed under the Creative Commons Attribution License, \\ which permits unrestricted use, distribution, and reproduction in any medium, provided the original work is properly cited.
}

\begin{abstract}
Endoscopic band ligation is regarded as the main therapeutic option for acute esophageal variceal bleeding, while sclerotherapy may be used in the acute setting if ligation is technically difficult. The incidence of difficult-to-perform band ligation in acute esophageal variceal bleeding, as well as the outcome of patients subjected to injection sclerotherapy as an alternative treatment, has not been clearly investigated. Our aim is to study the outcome of patients subjected to injection sclerotherapy in the acute setting of esophageal variceal bleeding when endoscopic band ligation is technically difficult to perform. We included 151 patients with acute esophageal variceal bleeding originnating from medium or large sized varices. All patients were planned for EBL as the 1st treatment option (EBL group 61.6\%), meanwhile, EIS using 5\% ethanolamine oleate was reserved as the 2nd treatment option when EBL was technically difficult (EIS group $38.4 \%$ ). The mean time to restore hemodynamic stability was significantly prolonged in the EIS group (11.5 \pm 6.5 hrs versus $9.5 \pm 5.0$ hrs, p 0.05). Initial control of bleeding was significantly higher in the EBL group versus the EIS group ( $96.7 \%$ vs $84.5 \%$, p 0.021). Re-bleeding was more among the EIS group $(42.9 \%$ vs $24.2 \%$, p 0.04$)$. There were no significant differences as regarding mortality and duration of hospital stay. So, a considerable proportion of cases presenting with acute variceal bleeding will have difficulty in performing EBL. In these patients, sclerotherapy is not a waning procedure with an accepted success rate, without much additional complications and without deranging mortality.
\end{abstract}

"Corresponding author.
Keywords: Esophageal Varices; Band Ligation; Injection Sclerotherapy

\section{INTRODUCTION}

The management of acute variceal bleeding remains a clinical challenge. Regarding the best endoscopic therapeutic option, a meta-analysis of 10 randomized controlled trials including 404 patients showed an almost significant benefit of endoscopic band ligation in the initial control of bleeding compared to sclerotherapy [1]. At the same time, Baveno IV and V consensuses had repeatedly confirmed that ligation is the recommended method of endoscopic therapy for acute esophageal variceal bleeding although sclerotherapy may be used in the acute setting if ligation is technically difficult $[2,3]$.

The incidence of difficulty to perform band ligation in acute esophageal variceal bleeding, as well as the outcome of patients subjected to injection sclerotherapy as an alternative treatment, has not been clearly investigated.

\section{AIM OF THE WORK}

Our aim is to study the outcome of patients subjected to injection sclerotherapy in the setting of acute esophageal variceal bleeding in case of technical difficulty to perform band ligation.

\section{PATIENTS AND METHODS}

This study was approved by the Hepatogastroenterology Department and the Research Board of Cairo University. It included 151 patients with acute bleeding from esophageal varices originating from medium and large sized varices. They were admitted to Gastroenterology unit of 
Air force Hospital, Cairo; during the period from 15 January 2010 till 15 July same year. Patients with bleeding gastric varices, bleeding small sized oesophageal varices, bleeding portal hypertensive gastropathy, hepatic coma or hepatocellular carcinoma were not included in the study.

Patients were resuscitated after relevant history taking and clinical examination. Stabilization of hemodynamics was firstly performed. Blood transfusion was initiated depending upon the severity of bleeding and hemo-dynamic status with a transfusion target hematocrit of $24 \%$ and/or hemoglobin of $8 \mathrm{~g} / \mathrm{dl}$. I.V antibiotics were routinely given. Octreotide was started whenever indicated in a dose of $50 \mu \mathrm{g}$ IV bolus, followed by continuous infusion $50 \mu \mathrm{g} / \mathrm{hr}$ for $2-5$ days. Further assessment was done including laboratory investigations and abdominal ultrasonography. The severity of bleeding was considered as: mild when pulse rate $<100 / \mathrm{min}$, orthostatic hypotension or cold extremities, moderate when pulse rate $100-120$ beats/min with restlessness or severe when pulse rate $>120$ beats $/ \mathrm{min}$, systolic blood pressure $<60$ $\mathrm{mmHg}$, severe pallor or oliguria [4]. Endoscopy session was scheduled once the patient's hemodynamics permitted after an informed and written consent. Emergency endotherapy was performed by a single endoscopist, all patients were planned for endoscopic band ligation (EBL) using the Saeed multi-band ligators manufactured by the Wilson-Cook Medical GI endoscopy company as the 1st treatment option to control the acute bleeding episode (EBL group) (Figure 1), meanwhile, endoscopic injection sclerotherapy (EIS) using ethanolamine oleate was reserved as a 2nd treatment option when EBL was technically difficult (only when the view of the bleeding source was obscured) (sclerotherapy group) (Figure 2).

Varices were assigned grades according to their shape and size: grade F1, small straight veins; grade F2,

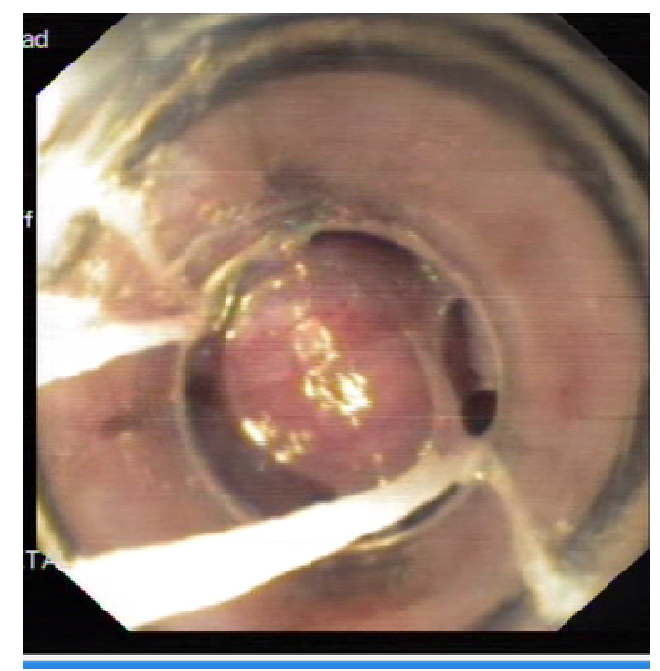

Figure 1. EVL to bleeding varices.

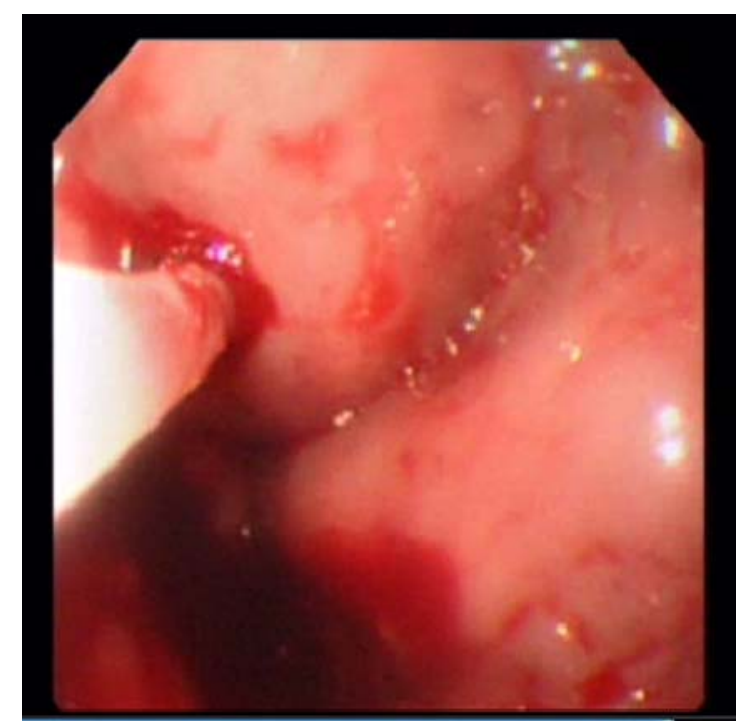

Figure 2. Sclerotherapy for bleeding varices.

slightly enlarged tortuous veins occupying less than onethird of the esophageal lumen; and grade F3, large coilshaped varices that occupied more than one-third of the esophageal lumen [5].

The assessment for treatment side-effects was performed during hospital stay and included monitoring of symptoms, physical examination and laboratory data. Complications were defined as untoward events related to treatment and require active therapy or prolonged hospitalization. All available patients in both groups were followed up for 42 days for clinical assessment, variceal re-bleeding, and hepatic de-compensation. Failure to control active bleeding was considered according to the UK guidelines [6] as transfusion requirement of 4 units or more and inability to achieve an increase in systolic blood pressure by $20 \mathrm{~mm} \mathrm{Hg}$ or to $70 \mathrm{~mm} \mathrm{Hg}$ or more, and/or inability to achieve a pulse rate reduction to less than $100 \mathrm{beat} / \mathrm{min}$ or a reduction of $20 \mathrm{beat} / \mathrm{min}$ from baseline pulse rate (within the first six hours). Or the occurrence of haematemesis from the six hour point, reduction in blood pressure of more than $20 \mathrm{~mm} \mathrm{Hg}$ from the six hour point and/or increase in pulse rate of more than $20 \mathrm{beat} / \mathrm{min}$ from the six hour point on two consecutive readings an hour apart, transfusion of 2 units of blood or more (over and above the previous transfusions) required to increase the haematocrit to above $27 \%$, or haemoglobin to above $9 \mathrm{~g} / \mathrm{l}$. Re-bleeding: was considered as the occurrence of new hematemesis or melena after a period of 24 hours or more of stable vital signs and hematocrit/hemoglobin following an episode of acute bleeding up to 42 days from the acute bleeding episode. Stoppage of bleeding: is considered when there is no hematemesis, stable hemoglobin concentration without blood transfusions, stable hemodynamic conditions at the beginning of the first 24-hour interval from time zero [2]. 
Patients' data were tabulated and processed using SPSS (10.0) statistical package. Quantitative variables were expressed by means and standard deviation. While qualitative data were expressed by frequency and percent. Qualitative variables were analyzed using Chi-square or Ficher's exact test when appropriate. Quantitative variables were analyzed using student's T-test or Friedmann's test when appropriate. In all tests $\mathrm{p}$ value was significant when $<0.05$.

\section{RESULTS}

This study included 151 patients with acute esophageal variceal bleeding. They were sub-grouped based on the type of endoscopic intervention into EBL (band ligation) group (93 patients $61.6 \%$ ) and EIS (sclerotherapy group) (58 patients $38.4 \%$ ).

The majority of patients in the EBL group had a mild bleeding episode $(64.5 \%)$ versus none in the sclerotherapy group. While the majority of those in the scerotherapy group had a moderate bleeding episode $(67.2 \%$, p 0.38). Time from admission to patient stabilization was significantly prolonged in the EIS group $11.5 \pm 6.5 \mathrm{hrs}$ versus $9.5 \pm 5.0 \mathrm{hrs}(\mathrm{p}$ 0.05) (Table 1). The post endoscopy outcome is demonstrated in (Table 2).

\section{DISCUSSION}

Bleeding from esophageal varices is a life-threatening complication of portal hypertension which accounts for most of cirrhosis-related mortalities [7,8]. Endoscopic therapy is an integral component of the management of acute variceal bleeding as well as prevention of recurrent bleeding [8,9]. Since it first evolved as a new therapeutic option, EBL has been regarded as a more effective modality than endoscopic injection sclerotherapy in the control of acute hemorrhage with less reported adverse events [10-12]. On the other hand, some studies still advocate the use of sclerotherapy as a better treatment option up to regarding it as the gold-standard treatment $[13,14]$.

Despite the routine standard of care given to patients presenting with hematemesis such as pharmacotherapy and gastric lavage, still up to one third of cases are actively bleeding during endoscopy, and it is this group of patients that poses a challenge to endoscopists and en-

Table 1. Base-line characteristics of EIS and EVL groups.

\begin{tabular}{|c|c|c|c|c|c|}
\hline \multirow{2}{*}{ Parameters } & \multicolumn{2}{|c|}{$\begin{array}{c}\text { EVL group } \\
\mathrm{N}: 93(61.6 \%)\end{array}$} & \multicolumn{2}{|c|}{$\begin{array}{c}\text { EIS Group } \\
\mathrm{N}: 58(38.4 \%)\end{array}$} & \multirow{2}{*}{$\mathrm{p}$} \\
\hline & $\mathrm{No} / \%$ & Mean/SD & $\mathrm{No} / \%$ & Mean/SD & \\
\hline Age (years) & 52 & \pm 3 & 53 & \pm 3 & 0.89 \\
\hline \multicolumn{6}{|l|}{ Sex } \\
\hline Male & 52 & $56 \%$ & 42 & $72.5 \%$ & \multirow{2}{*}{0.33} \\
\hline Female & 41 & $44 \%$ & 16 & $27.5 \%$ & \\
\hline Previous bleeding attacks & 48 & $51.6 \%$ & 33 & $56.9 \%$ & 0.63 \\
\hline \multicolumn{6}{|l|}{ Child Pugh class: } \\
\hline A & 9 & $9.7 \%$ & 4 & $6.9 \%$ & \\
\hline $\mathrm{B}$ & 37 & $39.8 \%$ & 25 & $43.1 \%$ & 0.057 \\
\hline $\mathrm{C}$ & 47 & $50.5 \%$ & 29 & $50 \%$ & \\
\hline \multicolumn{6}{|l|}{ Grade of varices } \\
\hline Grade F2 & 48 & $51.6 \%$ & 28 & $48.2 \%$ & 0.85 \\
\hline Grade F3 & 45 & $48 \%$ & 30 & $51.7 \% \%$ & \\
\hline Hemodynamic instability & 81 & $87.1 \%$ & 53 & $91.4 \%$ & 0.53 \\
\hline \multicolumn{6}{|l|}{ Severity of bleeding } \\
\hline Mild & 60 & $64.5 \%$ & 0 & $0 \%$ & \\
\hline Moderate & 24 & $25.8 \%$ & 39 & $67.2 \%$ & $<0.01$ \\
\hline Time from admission to endoscopy (hrs) & 9.5 & \pm 5 & 11.5 & \pm 6.5 & 0.05 \\
\hline
\end{tabular}


Table 2. Post-endoscopy outcome in both groups.

\begin{tabular}{|c|c|c|c|c|c|}
\hline \multirow{2}{*}{ Parameters } & \multicolumn{2}{|c|}{$\begin{array}{l}\text { EVL group } \\
\text { N: } 93(61.6 \%)\end{array}$} & \multicolumn{2}{|c|}{$\begin{array}{l}\text { EIS Group } \\
\text { N: } 58(38.4 \%)\end{array}$} & \multirow{2}{*}{$\mathrm{p}$} \\
\hline & $\mathrm{No} / \%$ & Mean/SD & $\mathrm{No} / \%$ & Mean/SD & \\
\hline Control of acute bleeding & 90 & $96.7 \%$ & 49 & $84.5 \%$ & 0.021 \\
\hline Re-bleeding & 22 & $24.2 \%$ & 21 & $42.9 \%$ & 0.04 \\
\hline Control of re-bleeding & $17 / 22$ & 77.35 & $11 / 19$ & $57.9 \%$ & 0.23 \\
\hline \multicolumn{6}{|l|}{$\begin{array}{l}\text { Incidence of complications among } \\
\text { different child-Pugh cases }\end{array}$} \\
\hline Child A & 1 & $1.1 \%$ & 2 & $3.4 \%$ & \\
\hline Child B & 8 & $8.6 \%$ & 14 & $24.1 \%$ & 0.079 \\
\hline Child C & 6 & $6.4 \%$ & 13 & $22.4 \%$ & \\
\hline Bacterial peritonitis & 6 & $6.4 \%$ & 11 & $19 \%$ & 0.01 \\
\hline Aspiration pneumonia & 0 & $0 \%$ & 1 & $1.7 \%$ & 0.41 \\
\hline Sepsis & 1 & $1.1 \%$ & 2 & $3.4 \%$ & 0.065 \\
\hline Bleeding esophageal ulcer & 1 & $1.1 \%$ & 2 & $3.4 \%$ & 0.065 \\
\hline Chest pain & 2 & $2.2 \%$ & 5 & $8.6 \%$ & 0.01 \\
\hline Fever & 1 & $1.1 \%$ & 2 & $3.4 \%$ & 0.065 \\
\hline Transient arrhythmias & 1 & $1.1 \%$ & 1 & $1.7 \%$ & 0.1 \\
\hline Nausea & 1 & $1.1 \%$ & 2 & $3.4 \%$ & 0.068 \\
\hline Transient dysphagia & 2 & $2.2 \%$ & 3 & $5.2 \%$ & 0.012 \\
\hline \multicolumn{6}{|l|}{ Mean hemoglobin (gm/dl) } \\
\hline Day 1 & 8.6 & \pm 0.34 & 8.1 & \pm 0.36 & 0.18 \\
\hline Day 5 & 8.8 & \pm 0.34 & 8.4 & \pm 0.31 & 0.45 \\
\hline Units of packed RBCs & 3.1 & \pm 1.07 & 4.1 & \pm 1.2 & 0.01 \\
\hline Hospital stay in days & 8.3 & \pm 1.9 & 9.1 & \pm 2.6 & 0.27 \\
\hline Total Mortality & 19 & $20.4 \%$ & 21 & $36.2 \%$ & 0.19 \\
\hline
\end{tabular}

dangers the life of the patient as it has been found to have a negative impact on survival $[7,15,16]$. In this situation banding may be technically difficult to perform in the presence of continued bleeding, and sclerotherapy may then be necessary $[2,3,9,17]$. So this means that, whether endoscopists fall for band ligation or sclerotherapy as the preferred treatment, the set up of an emergency endoscopic unit should be equipped with both and the endoscopists should be ready to switch between the 2 modalities.

How frequent is this situation encountered, what is the outcome and what are the sequaele, remained to be investigated. This was the rational to conduct this study. It was carried in the Air Force hospital on 151 patients with acute variceal bleeding. All included patients had acute esophageal variceal bleeding from medium or large sized varices, while other portal hypertensive bleeding sources were not included. To ensure homogeneity among these patients, they were all given the same standards of care such as gastric lavage and pharmacotherapy with octerotide and judicious volume expanders. All of them underwent endoscopy whenever they reached hemodyamic stability irrespective of time and all were endoscoped by a single operator. The plan at the time of endoscopy was to perform band ligation as a primary treatment option unless profuse bleeding was encountered to the extent of posing technical difficulty in visualizing and banding the bleeding varix, in the latter condition, switch to sclerotherapy was done.

The studied cases in both groups were comparable in terms of their demographic features. All patients had received pharmacotherapy by octerotide and yet, $38.4 \%$ of the studied cases were actively bleeding at endoscopy, profusely enough, to change the decision of treatment 
from band ligation to sclerotherapy. Terblanche et al. [16], stated that one third of cases are actively bleeding at the time of endoscopy, this finding was made before the advent of octreotide as a recommended treatment. In our study although octreotide was given, still a subset of patients similar to those reported by Terblanche were bleeding profusely at the time of endoscopy $(38 \%)$. Actually the therapeutic effects of octreotide on the portal and systemic hemmodynamics in patients with liver cirrhosis have yielded conflicting results, while some authors showed beneficial effects on the portal hemodynamics, others failed to show any beneficial effects. In an interesting study, Baik et al. [18] demonstrated that in patients with acute variceal bleeding, the main effect of octreotide on the HVPG was during the first minute after therapy, whereas thereafter the effect is not sustained and soon the HVPG reverts to base line after 5 mins of therapy. This might explain why patients were still bleeding during endoscopy.

The profuse bleeding at the time of endoscopy (as represented in the sclerotherapy group) was not influenced by the severity of liver disease (as both groups were comparable regarding Child-Pugh class), nor by the grade of varices at the time of endoscopy probably because bleeding might have temporarily reduced variceal size during endoscopy.

All patients underwent endoscopy after attaining hemodynamic stability, and yet the majority of these patients were hemodynamically unstable at the time of presentation $(87.1 \%$ in the EBL group and $91.4 \%$ in the scerotherapy group), this emphasizes the role of the preendoscopic standards of care given to the patients like volume restitution and maintaining the aerobic metabolism by restoring an appropriate delivery of oxygen to the tissues (which depends on oxygen saturation, cardiac output, and hemoglobin concentration) [19]. This also explains why the scerotherapy group underwent endoscopy after a significantly longer time than the EBL group $(9.5 \pm 5 \mathrm{hrs}$ in the EBL group versus $11.5 \pm 6.5 \mathrm{hrs}$ in the sclerotherapy group) and had a significantly more amount of transfused packed RBCs as compared to the EBL group ( $4.1 \pm 1.2$, versus $3.1 \pm 1.07 ; \mathrm{p} 0.01)$.

The next point to highlight in this study is the outcome of patients following the emergency endoscopy, it is clear that rapid switching from conventional EBL to sclerotherapy in our patients saved the time that could have been spent over getting a clear view so as to perform EBL, which of course could have endangered the patients' lives. That is why there were no reported differences in the mortalities between the 2 groups nor the duration of hospital stay. However, some of the unfavorable outcomes were significantly reported among the sclerotherapy than the EBL groups. The initial success to control bleeding for both techniques is compatible with the universally reported figures (around 90\%) [20]. However, it was significantly higher in the EBL versus EIS groups (96.7\% versus $84.5 \%$; $p$ 0.02). Also, bleeding recurrence was significantly less in the EBL versus the EIS groups $(24.2 \%$ versus $42.9 \%$; p 0.04). Lo et al. [7], reported $17 \%$ rate of re-bleeding with EBL vs. $33 \%$ with EIS, Villanueva et al. [11], reported $12 \%$ incidence rate for re-bleeding for EBL versus $21 \%$ for EIS. Krige et al. [14], reported that even under optimal conditions, currently available treatment options fail to control initial variceal bleeding or prevent early re-bleeding in up to $20 \%$ of patients. The overall analysis of these figures reveals that they match those reported by other authors. However, it is important to emphasize that these studies were randomized and it is supposed that patients with severe bleeding were homogenously distributed among both the EBL and EIS groups. This was not the case in this study, where the EIS group was a special grouping for those who were actively bleeding and difficult to perform EBL as explained by the significantly higher incidence of moderate and severe bleeding attacks among the EIS group. So the less success rates we encountered in this situation, where the technique might have been deranged due to the severe bleeding, is rather accepted. On the other hand, since the severity of the initial rebleed has been one of the contributing factors to recurrent bleeding [21], this again explains why the sclerotherapy group had a higher incidence of variceal rebleeding.

The other reported adverse events like chest pain, dysphagia and bacterial peritonitis were significantly higher in the EIS than the EBL group. These can be attributed mainly to the type of the technique and to a less extent to the severity of bleeding. Randomized trials that compared EBL to scerotherapy have yielded similar findings, without essentially having difference in the severity of bleeding between both arms. Most of these studies have reported that EBL is generally a safer technique than EIS because it involves a mechanical, less invasive method of variceal obliteration with less systemic and local complications involving the esophageal wall $[7,11,22-29]$. For example our data of peritonitis were $19 \%$ with EIS versus $6.4 \%$ with EBL (p 0.01). This matches with Laine et al. [24], who reported $18 \%$ incidence rate of peritonitis in EIS vs. $15.8 \%$ in EBL.

\section{CONCLUSION}

About one third of cases presenting with acute variceal bleeding will have difficult-to-perform EBL due to the severity of active bleeding at the time of endoscopy. In these patients, sclerotherapy is not a waning procedure and is still a technique that can be resorted to with an accepted success rate, without additional complications and without deranging mortality. 


\section{ACKNOWLEDGEMENTS}

The authors appreciate the contribution made by Dr Mohamed ElGouhary in the execution of this work

\section{REFERENCES}

[1] Garcia-Pagan, J.C. and Bosch, J. (2005) Endoscopic band ligation in the treatment of portal hypertension. Nature Clinical Practice Gastroenterology \& Hepatology, 2, 526535. doi: $10.1038 /$ ncpgasthep 0323

[2] De Franchis, R. (2005) Evolving consensus in portal hypertension. Report of the Baveno IV consensus workshop on methodology of diagnosis and therapy in portal hypertension. Journal of Hepatology, 43, 167-176. doi:10.1016/j.jhep.2005.05.009

[3] De Franchis, R., Bosch, J., Burroughs, A.K., D'Amico G., Garcia-Tsao, G., Grace, N.D., et al. (2010) Revising consensus in portal hypertension: Report of the Baveno $\mathrm{V}$ consensus workshop on methodology of diagnosis and therapy in portal hypertension. Journal of Hepatology, 53, 762-768. doi:10.1016/j.jhep.2010.06.004

[4] Del Olmo, J.A., Peña, A., Serra, M.A., Wassel, A.H., Benages, A. and Rodrigo, J.M. (2000) Predictors of morbidity and mortality after the first episode of upper gastrointestinal bleeding in liver cirrhosis. Journal of Hepatology, 32, 19-24. doi:10.1016/S0168-8278(01)68827-5

[5] Japanese Research Society for Portal Hypertension (1980) The general rules for recording endoscopic findings on esophageal varices. Japanese Journal of Surgery, 10, 8487. doi: $10.1007 / \mathrm{BF} 02468653$

[6] Jalan, R. and Hayes, P.C. (2000) UK guidelines on the management of variceal haemorrhage in cirrhotic patients. Gut, 46, iii1-iii15. doi:10.1136/gut.46.suppl_3.iii1

[7] Lo, G.H., Lai, K.H., Cheng, J.S., Lin, C.K., Huang, J.S., Hsu, P.I., et al. (1997) Emergency banding ligation versus sclerotherapy for the control of active bleeding from esophageal varices. Hepatology, 25, 1101-1104. doi:10.1002/hep.510250509

[8] Krige, J.E., Shaw, J.M. and Bornman, P.C. (2005) The evolving role of endoscopic treatment for bleeding esophageal varices. World Journal of Surgery, 29, 966-973. doi:10.1007/s00268-005-0138-2

[9] Garcia-Tsao, G., Sanyal, A.J., Grace, N.D. and Carey, W. (2007) Prevention and management of gastroesophageal varices and variceal hemorrhage in cirrhosis. Hepatology, 46, 922-938. doi:10.1002/hep.21907

[10] Avgerinos, A., Armonis, A., Stefanidis, G., Mathou, N., Vlachogiannakos, J., Kougioumtzian, A., et al. (2004) Sustained rise of portal pressure after sclerotherapy, but not band ligation, in acute variceal bleeding in cirrhosis. Hepatology, 39, 1623-1630. doi:10.1002/hep.20236

[11] Villanueva, C., Piqueras, M., Aracil, C., Gómez, C., López-Balaguer, J.M., Gonzalez, B., et al. (2006) A randomized controlled trial comparing ligation and sclerotherapy as emergency endoscopic treatment added to somatostatin in acute variceal bleeding. Journal of Hepatology, 45, 560-567. doi:10.1016/j.jhep.2006.05.016
[12] Garcia-Tsao, G., Bosch, J. and Groszmann, R.J. (2008) Portal hypertension and variceal bleeding-Unresolved issues. Summary of an American Association for the study of liver diseases and European Association for the study of the liver single-topic conference. Hepatology, 47, 1764-1772. doi:10.1002/hep.22273

[13] Burroughs, A.K. and Triantos, C.K. (2008) Predicting failure to control bleeding and mortality in acute variceal bleeding. Journal of Hepatology, 48, 185-188. doi:10.1016/j.jhep.2007.11.006

[14] Krige, J.E., Shaw, J.M., Bornman, P.C. and Kotze, U.K. (2009) Early re-bleeding and death at 6 weeks in alcoholic cirrhotic patients with acute variceal bleeding treated with emergency endoscopic injection sclerotherapy. South African Journal of Surgery, 47, 72-74,76-79.

[15] Cello, J.P., Grendell, J.H., Crass, R.A., Trunkey, D.D., Cobb, E.E. and Heilbron, D.C. (1984) Endoscopic sclerotherapy versus portacaval shunt in patients with severe cirrhosis and variceal hemorrhage. New England Journal of Medicine, 311, 1589-1594. doi:10.1056/NEJM198412203112501

[16] Terblanche, J., Kahn, D. and Bornman, P.C. (1989) Longterm injection sclerotherapy treatment for esophageal varices. A 10-year prospective evaluation. Annals of Surgery, 210, 725-731. doi:10.1097/00000658-198912000-00006

[17] Bendtsen, F., Krag, A. and Møller, S. (2008) Treatment of acute variceal bleeding. Digestive and Liver Disease, 40, 328-336. doi:10.1016/i.dld.2007.12.005

[18] Baik, S.K., Jeong, P.H., Ji, S.W., Yoo, B.S., Kim, H.S., Lee, D.K., et al. (2005) Acute hemodynamic effects of octreotide and terlipressin in patients with cirrhosis: A randomized comparison. American Journal of Gastroenterology, 100, 631-635. doi:10.1111/j.1572-0241.2005.41381.x

[19] García-Pagán, J.C., Reverter, E., Abraldes, J.G. and Bosch, J. (2012) Acute variceal bleeding. Seminars in Respiratory and Critical Care Medicine, 33, 46-54. doi:10.1055/s-0032-1301734

[20] Sarin, S.K., Govil, A., Jain, A.K., Guptan, R.C., Issar, S.K., Jain, M., et al. (1997) Prospective randomized trial of endoscopic sclerotherapy versus variceal band ligation for esophageal varices: Influence on gastropathy, gastric varices andvariceal recurrence. Journal of Hepatology, 26, 826-832. doi:10.1016/S0168-8278(97)80248-6

[21] de Franchis, R. and Primignani, M. (2001) Natural history of portal hypertension in patients with cirrhosis. Clinics in Liver Disease, 5, 645-663. doi:10.1016/S1089-3261(05)70186-0

[22] Stiegmann, G.V., Goff, J.S., Michaletz-Onody, P.A., Korula, J., Lieberman, D., Saeed, Z.A., et al. (1992) Endoscopic sclerotherapy as compared with endoscopic ligation for bleeding esophageal varices. New England Journal of Medicine, 326, 1527-1532. doi:10.1056/NEJM199206043262304

[23] Jensen, D.M., Kovacs, T.O.G. and Randall, G.M. (1993) Initial results of randomised prospective study of emergency banding versus esclerotherapy for bleeding gastric or esophageal varices. Gastrointestinal Endoscopy, 39. 
[24] Laine, L., El-Newihi, H.M. and Migikovsky, B. (1993) Endoscopic ligation compared with sclerotherapy for the treatment of bleeding esophageal varices. Annals of Internal Medicine, 119, 1-7. doi:10.7326/0003-4819-119-1-199307010-00001

[25] Lo, G.H., Lai, K.H., Chang, C.F., Shen, M.T., Jeng, J.S., Huang, R.L., et al. (1994) Endoscopic injection sclerotherapy vs. endoscopic variceal ligation in arresting acute variceal bleeding for patients with advanced hepatocellular carcinoma. Journal of Hepatology, 21, 1048-1052. doi:10.1016/S0168-8278(05)80616-6

[26] De la Peña, J., Rivero, M., Sanchez, E., Fábrega, E., Crespo, J. and Pons-Romero, F. (1999) Variceal ligation compared with endoscopic sclerotherapy for variceal hemorrhage: Prospective randomized trial. Gastrointestinal Endoscopy, 49, 417-423.
doi:10.1016/S0016-5107(99)70036-2

[27] Patch, D. and Dagher, L. (2001) Acute variceal bleeding: General management. World Journal of Gastroenterology, 7, 466-475.

[28] Zargar, S.A., Javid, G., Khan, B.A., Shah, O.J., Yattoo, G.N., Shah, A.H., et al. (2005) Endoscopic ligation vs. sclerotherapy in adults with extrahepatic portal venous obstruction: A prospective randomized study. Gastrointestinal Endoscopy, 61, 58-66. doi:10.1016/S0016-5107(04)02455-1

[29] Xu, L., Ji, F., Xu, Q.-W. and Zhang, M.-Q. (2011) Risk factors for predicting early variceal re-bleeding after endoscopic variceal ligation. World Journal of Gastroenterology, 17, 3347-3352. doi:10.3748/wig.v17.i28.3347 